\title{
The Hoffmann-Schiff dichotomy: on the reaction between chloral and amines
}

\author{
Linda M. Mascavage, ${ }^{\mathrm{a}}$ John Tierney, ${ }^{\mathrm{b}}$ Philip E. Sonnet, ${ }^{\mathrm{c}}$ and David R. Dalton ${ }^{\mathrm{c}}$ * \\ ${ }^{a}$ Department of Chemistry, Arcadia University, Glenside, PA, 19038, USA \\ ${ }^{b}$ Department of Chemistry, Pennsylvania State University, Media, PA, 19063, USA \\ ${ }^{c}$ Department of Chemistry, Temple University, Philadelphia, PA, 19122, USA \\ E-mail:david.dalton@temple.edu
}

In honor of Dr Bruce E. Maryanoff and Dr Cynthia A. Maryanoff

\begin{abstract}
In the nearly two centuries since the discovery of chloral (2,2,2-trichloroacetaldehyde), numerous nitrogenous reactants have been used to generate products resulting from attack at the carbonyl group by nitrogen. The resulting tetrahedral species, a carbinolamine, is often unstable and has been reported to lose water to produce an imine as well as to lose chloroform to produce an amide. We find that the path, and hence the product, is a function of the electron density at the nitrogen of the reacting amine. The weaker arylamines produce imine whilst the more strongly basic alkylamines produce amide.
\end{abstract}

Keywords: $A b$ initio calculations, basicity, aldehydes, amines, density functional calculations

\section{Introduction}

In the first issue (1832) of Annalen der Pharmacie (later to become Justus Liebig's Annalen der Chemie) Justus Liebig published an abstract of his studies on the chlorination of ethanol. He subsequently provided (in the second issue) the full details of his investigations of the products of that reaction, one of which was chloral (trichloroacetaldehyde). ${ }^{1}$ Little more of substance was published on the reactions of chloral until, nearly forty years later, Oscar Jacobsen showed that chloral reacted with amides to provide simple addition products (trichloromethylcarbinolamines) that retained the carbonyl oxygen (as a hydroxyl) as well as the trichloromethyl group. ${ }^{2}$ Shortly thereafter August Hofmann reported that when chloral reacted with 1,2-diaminoethane (ethylenediamine) a bis- $N$-formylamide and chloroform resulted; ${ }^{3}$ and, subsequently, Hugo Schiff showed that chloral reacts with aryl amines to produce imines (Schiff bases) and 1,1-bis-(aryl amines). ${ }^{4}$

As part of continuing research into the nature of reactions of amines with the carbonyl group ${ }^{5}$ we affirmed in the laboratory what had been previously expressed about the different products 
produced in the reactions of chloral. ${ }^{6}$ Additionally, we note that it has generally been found ${ }^{7}$ that when allowed to react with chloral, aromatic amines, often $6 \mathrm{pKa}$ units less basic than their aliphatic counterparts, produce imines ("Schiff bases") whilst aliphatic amines produce Nalkylformamides.

We report here calculations that clarify the nature of these reactions. They are consistent with the view that nitrogen basicity in an intermediate carbinolamine determines the path followed in subsequent fragmentations.

\section{Computational Methods}

Computations were conducted using the Gaussian G03 (Revision-E.01) suite of computational tools. ${ }^{8}$ We initially optimized all structures using the Hartree-Fock, HF/6-31G(d) method. More accurate energies were then obtained using (1) MP2/6-31+G(d,p) and (2) B3LYP/6-31+G(d,p) $)^{10}$ methods. Because density functional theory (DFT) is widely used in computational and theoretical chemistry, ${ }^{11}$ we selected $\mathrm{B} 3 \mathrm{LYP} / 6-31+\mathrm{G}(\mathrm{d}, \mathrm{p})$ for obtaining full geometry optimizations as well. Transition structures were obtained using the quasi-Newton synchronous transit (QST3) method ${ }^{12}$ and a single imaginary frequency was noted as confirmation of a saddle point. Intrinsic reaction coordinate (IRC) following ${ }^{13}$ produced paths that linked the transition structures to their respective potential energy wells. We note that default values for the convergence criteria in the IRC program often failed, perhaps because the PE surfaces were relatively flat (that is the coordinate changes accompanying normal step sizes produced insignificant $\Delta \mathrm{E}$ changes). In these cases we employed Internal Options procedures (IOp $1 / 7=$ $50)^{14}$ that are available in Gaussian G03.

As expected, several potential wells were located for both the reactant and product complexes; usually these involved slightly altered positions of the water molecules. We report energy values only of the lowest energy complexes we found and which, additionally, we identified as connected to a transition structure that had been found. The various isomeric complexes differed little in energy and hence would be rapidly equilibrating.

Elimination of chloroform from the carbinol intermediate to yield formamide could, in principle, also be accommodated by formation of an azaenol, but since this process was attended by considerably greater potential energies, the azaenols were not considered further (see Supplementary Materials).

\section{Results and Discussion}

Considerable experimental evidence has accumulated to suggest that the reversible addition of nucleophiles to the carbon of a carbonyl group in solution profits from participation by protic solvents or adventitious water engaging in hydrogen bonding to the oxygen of the carbonyl 
group in the rate determining step. ${ }^{15}$ The $\mathrm{pH}$ rate-profile for most such addition processes (maximizing at or near $\mathrm{pH}=6.0$ ) is consistent with this generalization. ${ }^{16}$ Although more extensive proton networking mechanisms may obtain, the observations are consistent with a concerted cyclic process of prototropy. ${ }^{17}$ We therefore depicted the complexes for reactants, products and transition structures to involve two water molecules thus generating an eightmembered array for the eliminations.

Transition structures for the collapse of the intermediate carbinolamine alternately to a formamide or an $E$-imine are given in Figure 1. For loss of chloroform to produce an amide, 1 and 2, the energy rises as the $\mathrm{C}-\mathrm{CCl}_{3}$ distance lengthens. This rise is tempered by the greater ability of the alkyl residue on nitrogen to lend electron density to the developing positive charge on the carbinol carbon The greater basicity of the alkyl-substituted nitrogen can better accomplish that end. This theme is carried through to an earlier barrier for the reaction of $\mathbf{1}$ $\left(\mathrm{C}-\mathrm{CCl}_{3}: 259 \mathrm{pm}\right.$ for $1 ; 267 \mathrm{pm}$ for 2$)$ which expresses the greater stability of the $\mathrm{N}$ alkylformamide that is being generated.

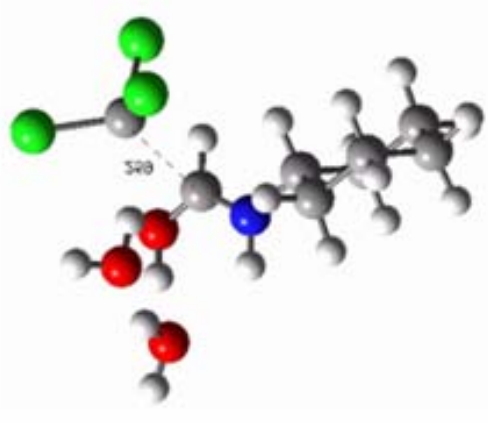

1

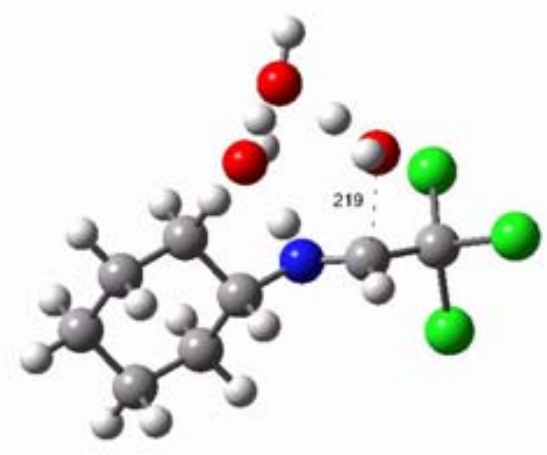

3

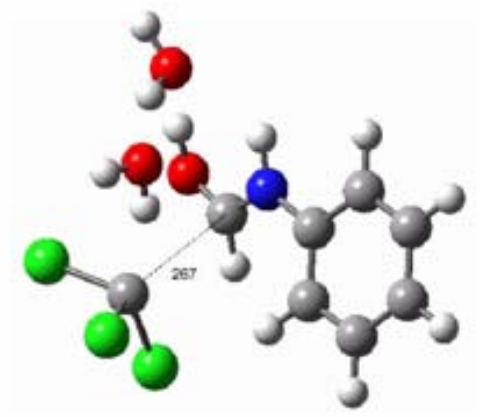

2

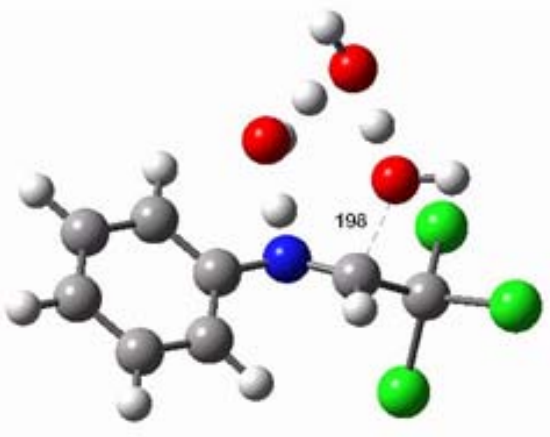

4

Figure 1. Transition structures obtained at the $B 3 L Y P / 6-31+G(d, p)$ level of accuracy for fragmentation of carbinolamines: 1 ( $\mathrm{G}=$ cyclohexyl, yielding formamide); $\mathbf{2}(\mathrm{G}=$ phenyl, yielding formamide); 3 ( $\mathrm{G}=$ cyclohexyl, yielding $E$-imine); 4 ( $\mathrm{G}=$ phenyl, yielding $E$-imine). Distances are given in $\mathrm{pm}$. 
Loss of water to form an imine should similarly benefit from electron donation of the nitrogen, but in this instance the barrier is lowered more effectively by delocalization of $\pi$ electron density from the aryl ring to the developing imine. Again, the transition barrier is earlier for the more stable product structure; the relevant $\mathrm{C}-\mathrm{OH}$ distances are: 3, $219 \mathrm{pm} ; \mathbf{4}, 198 \mathrm{pm}$; i.e., shorter for the favored elimination pathway. A cartoon representation of the processes that may be occurring is shown in Scheme 1 below. Here, both urea and acetamide are shown as halting at the trichloromethylcarbinol stage as neither is basic enough for proton removal.

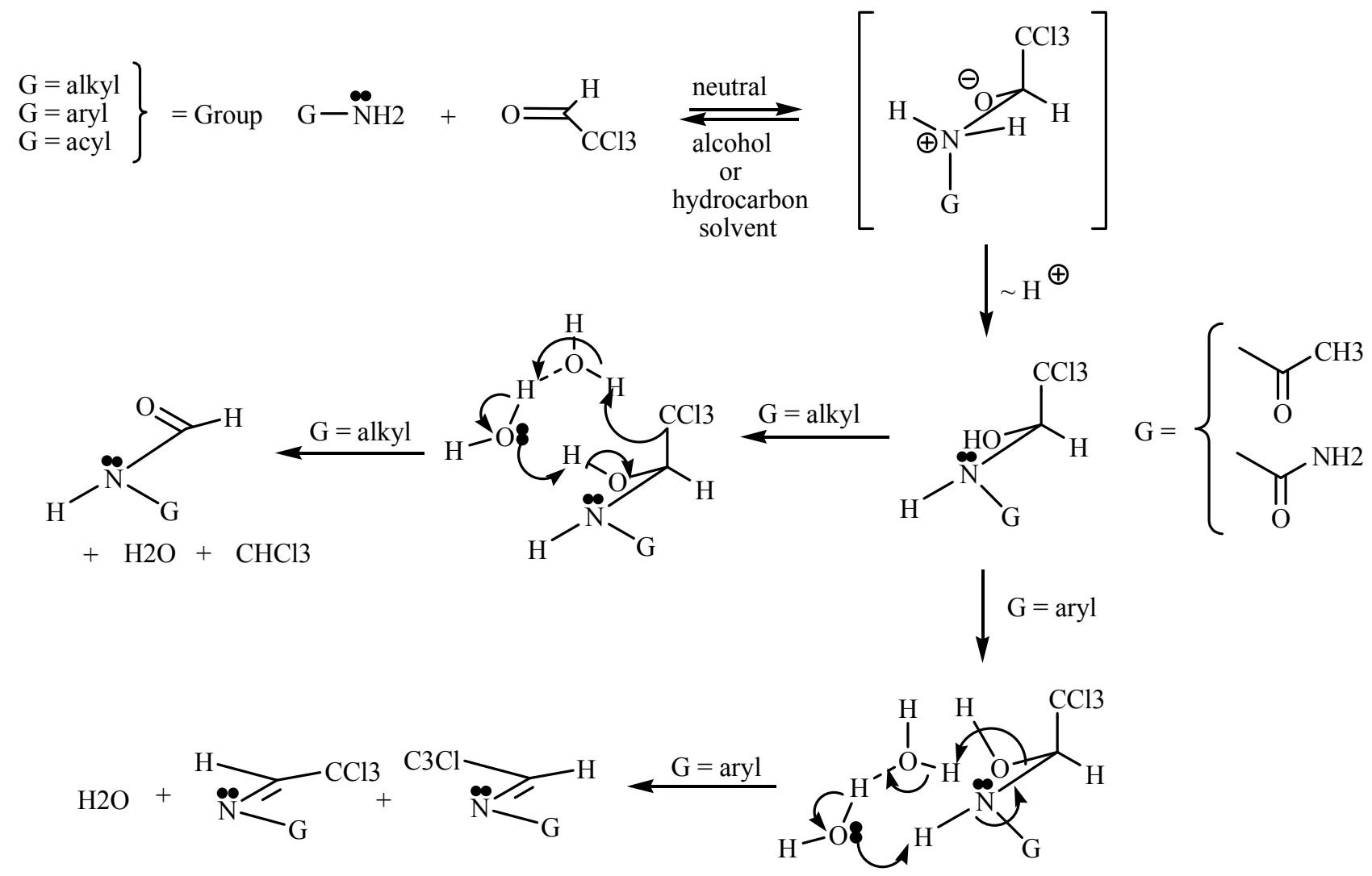

Scheme 1. Reactions of several nitrogen compounds with chloral. 
Table 1. Relative energies (sum of electronic and zpe) of structures by several methods of calculation (kcal/mol).

\begin{tabular}{|c|c|c|c|c|c|c|}
\hline \multicolumn{4}{|c|}{ Aniline $+\operatorname{chloral}(\mathrm{G}=\mathrm{Ar})$} & \multicolumn{3}{|c|}{ Cyclohexylamine + chloral $(\mathrm{G}=\mathrm{R})$} \\
\hline Structure & Method $1^{\mathrm{a}}$ & Method $2^{\mathrm{b}}$ & Method $3^{\mathrm{c}}$ & Method $1^{\mathrm{a}}$ & Method $2^{\mathrm{b}}$ & Method $3^{\mathrm{c}}$ \\
\hline Chloral, G-NH $2,2 \mathrm{~W}^{\mathrm{d}}$ & & & 26.4 & & & 26.6 \\
\hline Reactant complex & & & 5.3 & & & -13.5 \\
\hline TS to carbinolamine & & & 20.3 & & & 17.9 \\
\hline Product carbinolamine & & & 3.6 & & & -3.1 \\
\hline Reacting carbinolamine & 0.0 & 0.0 & 0.3 & 0.0 & 0.0 & 0.0 \\
\hline TS to Amide & 42.0 & 36.6 & 36.8 & 34.5 & 16.2 & 30.2 \\
\hline Amide complex & -13.0 & -15.4 & -13.2 & -4.6 & -19.4 & -19.7 \\
\hline Reacting carbinolamine & 0.0 & 0.0 & 0.3 & 0.0 & 0.0 & 1.8 \\
\hline TS to Imine & 24.4 & 35.4 & 34.8 & 41.0 & 40.0 & 32.0 \\
\hline Imine complex & -17.3 & 2.8 & 5.3 & 3.1 & 1.2 & 2.4 \\
\hline
\end{tabular}

${ }^{\mathrm{a}} \mathrm{MP} 2 / 6-31+\mathrm{G}(\mathrm{d}, \mathrm{p}) / / \mathrm{HF} / 6-31 \mathrm{G}(\mathrm{d})$ corrected for zpe using HF frequency calculation scaled by 0.9135 ;

${ }^{b} \mathrm{~B} 3 \mathrm{LYP} / 6-31+\mathrm{G}(\mathrm{d}, \mathrm{p}) / / \mathrm{HF} / 6-31 \mathrm{G}(\mathrm{d})$ corrected for zpe using HF frequency calculation;

${ }^{\mathrm{c}} \mathrm{B} 3 \mathrm{LYP} / 6-31+\mathrm{G}(\mathrm{d}, \mathrm{p}) ;{ }^{\mathrm{d}}$ individual energies of chloral, the amine, and 2 waters $(\mathrm{W})$;

The picture that emerges from the data of Table 1 indicates exothermic association of chloral with the amines $\left(-21.1 \mathrm{kcal} / \mathrm{mol}\right.$ when $\mathrm{G}=\mathrm{C}_{6} \mathrm{H}_{5} ;-40.1 \mathrm{kcal} / \mathrm{mol}$ when $\left.\mathrm{G}=\mathrm{C}_{6} \mathrm{H}_{11}\right)$. Barriers for the formation (and dissociation) of the carbinolamines are routinely lower than those leading forward from carbinolamine to imine or amide products, which is consistent with the occasional report of isolation of the intermediate carbinolamines (see reference 2 for the originally reported example). In all instances the barriers to amides from carbinolamines from the weaker arylamines $(\mathrm{G}=$ phenyl) are higher in energy than those leading to trichloromethyl-imines. Exactly the opposite obtains for the carbinolamines bearing the more basic nitrogen $(\mathrm{G}=$ cyclohexyl). In other computations where chloral was reacted with urea $\left(\mathrm{G}=\mathrm{NH}_{2}\right)$ and acetamide $\left(\mathrm{G}=\mathrm{CH}_{3}\right)$ the barriers to forming the carbinolamines were also lower than those leading to amides and imines in concert with reported isolations of the respective carbinolamines ${ }^{2,7}$ (see Supporting Information).

The computationally favored product from urea was the amide, and that from the acetamide was the imine, in concert with the notion that the donor strength of " $G$ " determines the pathway for carbinolamine decomposition. The situation is illustrated graphically for the DFT optimizations (Figure 2). 


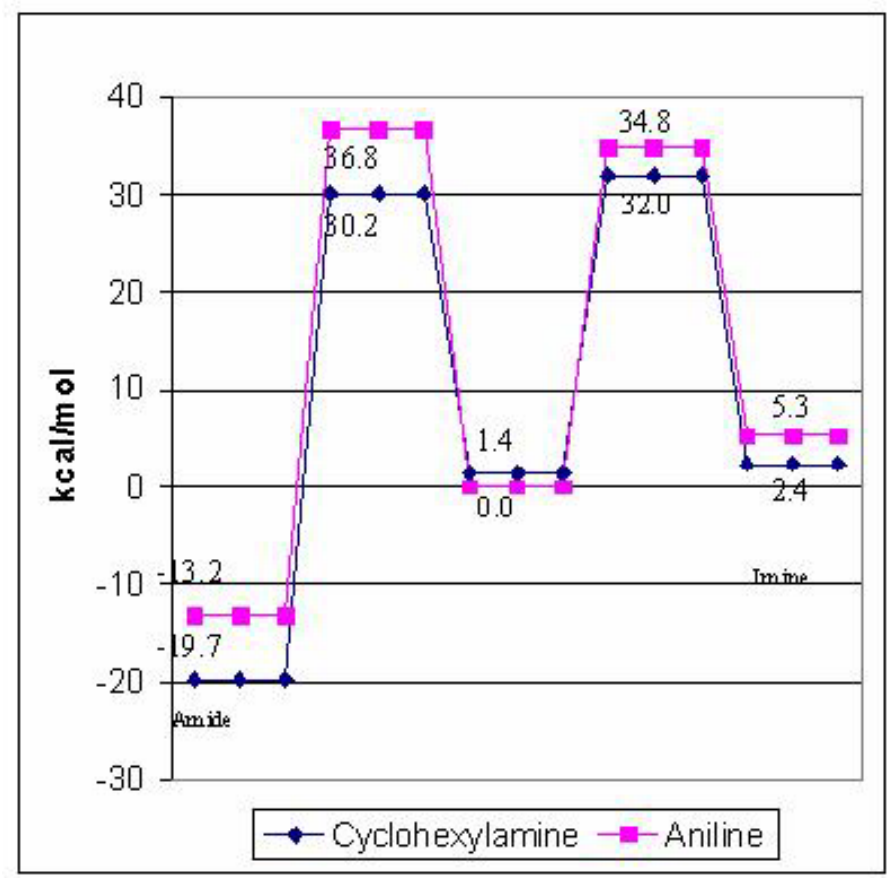

Figure 2. The B3LYP/6-31+G(d,p) of Table 1 presented graphically.

\section{Conclusions}

The long-standing Hoffmann-Schiff dichotomy is explained on the basis of nitrogen basicity. Thus, for the reaction of chloral with weak bases such as arylamines, the weakly held proton on nitrogen is lost along with the carbinol $\mathrm{OH}$ forming water and yielding imines. Additionally, the aryl group permits delocalization of electron density as the imine forms. Stronger bases, such as alkylamines, bind the proton on nitrogen more strongly and so lose chloroform to yield formamides. The delocalization of nitrogen lone pair electron density helps stabilize the forming $\mathrm{N}$ alkylamide.

\section{References}

1. Liebig, L. Ann. Pharm. 1832, 1, 31, 182.

2. Jacobson, O. Liebig's Ann. 1871, 157, 243.

3. Hofmann, A. W. Chem. Ber 1872, 5, 240.

4. Schiff, H. Liebigs Ann. 1875, 177, 227.

5. (a) Mascavage, L. M.; Sonnet. P.E.; Dalton, D. R. J. Org. Chem. 2006, 71, 3435 and earlier papers.(b) Sonnet, P. E.; Mascavage, L. M.; Dalton, D. R. Bioorg. Med. Chem. Let. 2008, 18, 744. 
6. Issac, R.; Tierney, J.; Mascavage, L. M.; Findeisen, A.; Kilburn, J. J. Heterocyclic Comm., 1996, 2, 227 and references therein.

7. Luknitskii, F. I. Chem. Rev. 1975, 75, 259.

8. Gaussian 03, G03, Revision-E.01, Frisch, M. J.; Trucks, G. W.; Schlegel, H. B.; Scuseria, G.E.; Robb, M. A.; J. Cheeseman, J. R.; Montgomery, Jr, J. A.; Vreven, T.; Kudin, K. N.; Burant, J.C.; Millam, J. M.; Iyengar, S. S.; Tomasi, J.; Barone, V.; Mennucci, B.; Cossi, M.; Scalmani, G.; Rega, N.; Petersson, G. A.; Nakatsuji, H.; Hada, M.; Ehara, M.; Toyota, K.; Fukuda, R.; Hasegawa, J.; Ishida, M.; Nakajima, T.; Honda, Y.; Kitao, O.; Nakai, H.; Klene, M.; Li, X.; Knox, J. E.; Hratchian, H. P.; Cross, J. B.; Adamo, C.; Jaramillo, J.; Gomperts, R.; Stratmann, R. E.; Yazyev, O.; Austin, A. J.; Cammi, R.; Pomelli, C.; Ochterski, J. W.; Ayala, P. Y.; Morokuma, K.; Voth, G.A.; Salvador, P.; Dannenberg, J. J.;;; Zakrzewski, V. G.; Dapprich, S.; Daniels, A. D.; Strain, M. C.; Farkas, O.; Malick, D. K.; Rabuck, A. D.; Raghavachari, K.; Foresman, J. B.; Ortiz, J. V.; Cui, Q.; Baboul, A. G.; Clifford, S.; Cioslowski, J.; Stefanov, B. B.; Liu, G.; Liashenko, A.; Piskorz, P.; Komaromi, I.; Martin, R. L.; Fox, D. J.; Keith, T.; Al-Laham, M. A.; Peng, C. Y.; Nanayakkara, A.; Challacombe, M.; P. Gill, P. M. W.; Johnson, B.; Chen, W.; M. Wong, M. W.; Gonzalez, C.; Pople, J. A. Gaussian, Inc., Pittsburgh PA, 2009.

9. Saebo, S.; Almlof, J. Chem. Phys. Lett. 1989, 83, 154.

10. (a) Becke, A. D.; J. Chem. Phys. 1993, 98, 5643. (b) Lee, C.; Yang, W.; Parr, R. G. Phys. Rev. B 1988, 37, 785. (c) Miehlich, B.; Savin, A.; Stoll, H.; Preuss, H. Chem. Phys. Lett. 1989, 157, 200.

11. (a) Koch, W.; Holthausen, M. C. A Chemist's Guide to Density Functional Theory, 2000, Wiley-VCH, Weinheim. (b) see Acosta-Silva, C.; Branchadell, V. J. Phys. Chem, 2007, 111, 12019 for more complete referencing and a valuable comparative study. (c) and for a discussion of current limitations of DFT methods, see Cohen, A. R.; Mori-Sánchez, P.; Yang, W. Science 2008, 321, 792.

12. Ayala, P. Y.; Schlegel, H. B. J. Chem. Phys. 1997, 107, 375.

13. (a) Gonzalez, C.; Schlegel, H. B. J. Chem. Phys. 1989, 90, 2154. (b) Gonzalez, C.; Schlegel, H. B. J. Phys. Chem. 1990, 94, 5523.

14. Frisch, A.; Cheeseman, J. R. eds. Gaussian 03 IOps Reference, 2003, Gaussian, Inc., Wallingford, CT. p. 3.

15. (a) It appears that the idea was originally put forth by Eigen, M. Discuss. Faraday Soc.1965, 39, 7. (b) Bell, R. P.; Millington, J. P.; Pink, J. M. N. Proc. Roy. Soc. 1968A, 303, 1. (c) Dahn, H.; H.; Aubort, H. J.-D. Helv. Chim. Acta 1968,51, 1348. (d) Haldna, Ü.; Erriline, L. E.-J.; Kuura, H. J. Organic Reactivity (Tartu) 1968, 5, 202. (e) Bell, R. P.; Critchlow, J. E. Proc. Roy. Soc. 1971A, 325, 35.

16. (a) Cordes, E. H.; Jencks, W. P. J. Am. Chem. Soc. 1963, 85, 2843. (b) Carey, F. A.; Sundberg, R. D. Advanced Organic Chemistry, Part A, 5th edn (corrected 2nd printing), 2007, Springer, NY p. 645 et seq.

17. Hall, N. E.; Smith, B. J. J. Phys. Chem. A 1998, 102, 4930. 